\title{
Metallographic Techniques for Revealing the Microstructure of the Expanded Austenite Case on Surface-Hardened Corrosion-Resistant Alloys
}

\author{
Sunniva R. Collins, Ph. D. ${ }^{1}$ \\ ${ }^{1}$ Associate Professor, Mechanical and Aerospace Engineering, Case Western Reserve University, \\ Cleveland, Ohio 44106 USA
}

Methods for hardening the surfaces of austenitic corrosion-resistant alloys (CRAs) (300 series stainless steels, nickel- and cobalt-based alloys, for example) have been researched since at least the 1980s [1, 2]. These methods include liquid sodium and cyanide salt bath treatments, plasma nitridation and carburization, ion implantation, and gaseous atmospheric heat treatments. Recent survey articles have reviewed the worldwide state of low temperature nitriding and carburizing of austenitic stainless steels $[3,4]$, and several academic conferences have been held in the past two decades on the topic of low-temperature thermochemical surface treatments of CRAs [5-9]. These processes result in a uniform (single phase) and highly conformal compositionally graded surface layer, highly enriched in carbon and/or nitrogen, ranging from 10 to $40 \mu \mathrm{m}$ thick, with a near surface hardness that can approach HV 1200 (over $70 \mathrm{HRC}$ ). The treatments usually occur at low temperatures (typically below $500^{\circ} \mathrm{C}$ ) and phase transformations are avoided. As an example, carbon concentrations at the surface of treated 316SS components have been verified by a variety of analytical methods to be on the order of 12 to 15 at. $\%$; up to 20 at.\% has been demonstrated on treated superaustenitic steels. The case remains austenitic and retains its ductility.

Application of low-temperature surface hardening processes may be transparent to the end user; that is, the surface will visually appear as it did prior to treatment. As only a layer comprising the first $25 \mu \mathrm{m}$ or so below the surface is affected by the treatment, it can be difficult to determine if a surface has been treated without resorting to destructive methods and optical microscopy. Two qualitative methods for examining treatment have been used: scratch hardness using calibrated files, and immersion in sodium hypochlorite solutions. These methods interrogate the case for hardness and corrosion response to a chloride-containing environment. Although they can differentiate a treated from a non-treated surface, they are not specific enough to be used for anything but a screening test. For detailed evaluation of case properties, quantitative methods providing enhanced spatial resolution are preferable. These include light-optical microscopy of metallographic cross sections, depth profiles of nano- or microhardness, and composition-depth profiles obtained through glow-discharge optical emission spectrometry (GD-OES) or calibrated Auger electron spectroscopy (AES) using a Scanning Auger microprobe (SAM) on a cross section. These methods are destructive, in that a component must be sectioned to evaluate the case. However, quantitative comparative data is obtained and can be used to develop metrics for the case.

The low-temperature carburized layer on austenitic stainless steel has been characterized using optical metallography. On a sectioned and etched specimen, the case appears as a relatively featureless, etch-resistant surface layer of approximately $25 \mu \mathrm{m}$. This layer is a diffusion gradient of carbon in solid solution in the austenite matrix. The structure of the case has been evaluated by X-ray diffraction, and has been shown to be expanded austenite. The lattice parameter of the austenite expands from $0.360 \mathrm{~nm}$ to $0.372 \mathrm{~nm}$ after treatment [10]. Other researchers, particularly those working in low-temperature nitriding processes, have called this structure S-phase [11-13]. Expanded austenite is a supersaturated solid solution without the precipitation of chromium-containing nitrides or carbides. Figure 1 shows metallographic evidence of improved corrosion resistance; the case is not etched by the Kane's reagent 
that reveals the microstructure of the core. The expanded austenite case is a non-equilibrium structure, where large amounts of either nitrogen or carbon (or both) are dissolved in the surface, and represents a condition far from equilibrium. After treatment, the temperature stability of this structure depends on minimizing exposure to temperature, as the carbon and/or nitrogen in solid solution will continue to diffuse into the matrix at temperatures approaching treatment temperatures of 350 to $550{ }^{\circ} \mathrm{C}$. After extended exposure, the case may no longer be present.

Optical metallography may also be used to identify carbonitrided surfaces, which show a dual-layer case on etching; and non-equilibrium carbides and nitrides (Fig. 2), which may form in the case under conditions of high treatment temperature or extensive time at treatment.

\section{References:}

[1] B. H. Kolster, VDI-Berichte, 506 (1983), p. 1-17, translation.

[2] U. Gramberg et al., VDI-Berichte, 506 (1983) p. 1-13, translation

[3] H. Dong, International Materials Reviews, 55 (2010) p. 65-98

[4] T. Bell, Surface Engineering, 18 (2002), p. 415-422

[5], Stainless Steel 2000, (Osaka, Japan, 2000) Institute of Materials, London, UK

[6] $1^{\text {st }}$ Symp. Surface Hardening of Stainless Steels, CWRU, Cleveland, OH, October 2007

[7] $2^{\text {nd }}$ Symp. Surface Hardening of Corrosion Resistant Alloys, CWRU, Cleveland, OH May 2010

[8] Nitriding Symp. 2: Las Vegas, NV, November 2010

[9] S. Collins, A. Heuer, Met Trans, 40A (2009), p. 1767

[10] Y. Cao et al., Acta Materialia, 51 (2003), p. 4171.

[II] Z. L. Zhang and T. Bell, $3^{\text {rd }}$ Intl. Congress Heat Treatment of Materials, Shanghai, 1983

[12] Z. L. Zhang and T. Bell, Surf. Eng., 1 (1985), p. 131-136.

[13] K. Ichii et al., Technol. Rep. Kansai Univ., 27 (1986), p. 135-144.
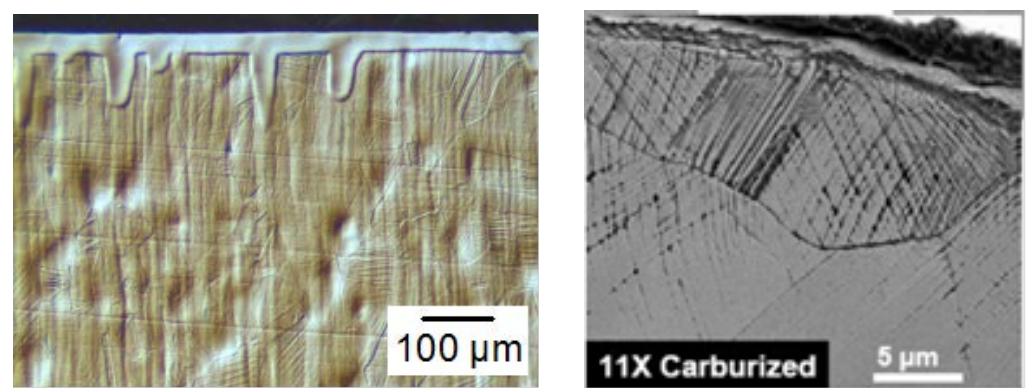

Figure 1. Metallographically prepared specimen of treated austenitic stainless steel. Etched with Kane's reagent. Courtesy A. Avishai, CWRU

Figure 2. Non-equilibrium carbides revealed in the case of a specimen that received multiple low-temperature carburization treatments. Etched using $\mathrm{HCl}: \mathrm{HNO}_{3}$ :Glycerol:HF. Courtesy CWRU 